\title{
O DESENHO NA EXPRESSÃO DE SENTIMENTOS EM CRIANÇAS HOSPITALIZADAS
}

\author{
Josianne Maria Mattos da Silva
}

\begin{abstract}
Resumo
$O$ artigo propõe uma reflexão sobre o atendimento psicológico à criança em situação de hospitalização. Abordao desenho infantil como uma forma de expressão que facilita a comunicação das crianças com a equipe de saúde, principalmente quando as mesmas encontram-se no estágio pré-operacional do desenvolvimento infantil. O presente texto compreende o desenho como um instrumento projetivo que possibilita que a realidade interna da criança seja representada por meio de símbolos. Trabalhos nesta área ampliam as possibilidades de intervenções, contribuindo com aqueles que lidam com crianças em situação de hospitalização, favorecendo a percepção de novas maneiras de se lidar com estes pacientes.

Palavras-chave: desenho; crianças hospitalizadas; sentimentos.

\section{THE DRAWING IN THE EXPRESSION OF FEELINGS IN HOSPITALIZED CHILDREN}

ABSTRACT:

The article is a reflection about the psychological attendance for hospitalized children. Considers the drawing like a form of expression that facilitates the communication of children with the health professionals, especially when them enter the pre-operational stage of child development. The text understand the drawing like a projective instrument allowing the representation of the internal reality of child through symbol. The theme expands the possibility of intervention with children, encouraging the perception of new ways of dealing with them.
\end{abstract}

Keywords: drawing; hospitalized child; feelings.

\footnotetext{
^ Psicóloga. Graduada em Psicologia e em bacharelado em Psicologia pela Universidade Federal de Pernambuco.

E-mail: josiannemattos@hotmail.com
} 


\section{INTRODUÇÃO}

O processo de hospitalização é permeado por perdas que desencadeiam um processo de luto. As perdas em questão estão especialmente relacionadas a três fatores, a saber: a doença (como significado da perda da saúde), a hospitalização (como perda da condição de pessoa, ou seja, a despersonalização), e, por fim, o tratamento, o qual está cerceado por atitudes invasivas e agressivas, desencadeando no indivíduo a sensação de impotência e perda da autonomia (FONGARO; SEBASTIANI, 1996).

A respeito da doença, esta acarreta num desequilíbrio à existência, no qual a pessoa perde sua condição de agente ativo para passivo em relação a aspectos de sua vida. Diante disso, as condições emocionais são essenciais na recuperação dos pacientes, tanto no processo de hospitalização em si quanto na maneira como a doença foi sedimentada no imaginário (ANGERAMI-CAMON, 2002).

Em se tratando de crianças, elas percebem a hospitalização como uma nova situação de vida em que há muitas mudanças em sua rotina, vivenciando situações com as quais devem se adaptar. Estas mudanças, decorrentes de sua nova condição, são geradoras de estresse (ALMEIDA, 2005). No processo de hospitalização, todos os procedimentos agressivos e bastante desagradáveis, podem mobilizá-las de maneira negativa (FREITAS, 2008).

O fato de estar hospitalizada, assim como os procedimentos médicos adotados e a própria doença em si, surge na percepção da criança como uma punição, um castigo, algo estreitamente relacionado a uma culpa subjacente. Dessa maneira, as relações doença/hospitalização/culpa/castigo irão sempre permear o pensamento da criança (OLIVEIRA, 1993).

Relacionado a isso, criança numa situação de hospitalização pode experimentar uma desordem emocional, aliada a uma dificuldade em expressar seus sentimentos, em traduzir o que sente em palavras. Esta dificuldade de expressão verbal, de se explicar, origina um conflito que se torna uma crise, o sintoma passa a ser, então, algo que se tem dificuldade de se expressar. (BARUS-MICHAEL, 2003)

Para Angerami-Camon (1984) o atendimento a crianças hospitalizadas deve ser dirigido para minimizar seu sofrimento, tendo como princípio a promoção da saúde não somente no âmbito físico. A isso Freitas (2008) acrescenta que neste ambiente a humanização é fundamental, visto que a criança não está necessitando somente de atenção nos aspectos relacionados à saúde física, mas também nas questões pessoais e sociais.

Nesse contexto, o desenho infantil e sua linguagem simbólica tornam-se elementos essenciais no acompanhamento às crianças hospitalizadas, visto que o mesmo é considerado por diversos autores (HAMMER, 1981; WINNICOTT, 1984; GOLDBERG, YUNES; FREITAS, 2005; ARFOUILLOUX, 1983) como sendo um instrumento por meio do qual a criança consegue expressar aquilo que não consegue dizer através da fala, possibilitando que entrem em contato com seu universo interior e que possam representá-lo. 
Este estudo surge da necessidade de se refletir sobre o atendimento psicológico à criança hospitalizada e tem como objetivo demonstrar a importância de um trabalho com as crianças no qual o desenho seja utilizado, considerado como uma forma de expressão que facilita a comunicação da criança com a equipe. A relevância de estudos nesta área está na possibilidade de contribuir com aqueles que lidam com crianças neste contexto, favorecendo a percepção de novas maneiras de se lidar com as mesmas.

É preciso lembrar que o desenho infantil pode ser utilizado na intervenção com crianças a partir dos dois anos de idade, pois antes disto eles não apresentam função simbólica; tal função surge quando a criança adentra no estágio pré-operacional do desenvolvimento infantil - em referência à teoria do desenvolvimento infantil de Piaget (1971). Uma das características desta fase é a entrada da criança no universo dos símbolos; assim, por volta dos dois anos, seus desenhos, ainda que não tenham um formato definido, já comunicam algo de maneira simbólica - conforme mencionado por Di Leo (1985) - ; podendo representar algo que está além do que pode ser percebido numa análise objetiva de seu desenho.

\section{A CRIAnÇa hospitalizada}

A hospitalização para a criança é um processo de muitas perdas caracterizadas pelo afastamento da família, da escola, dos amigos e de seus brinquedos. Valladares (2003) destaca alguns sintomas mais comuns a estes pacientes, como: sentimentos de culpa, reação de angústia, luto, medo de morrer, insegurança, tendência à fobia (agulhas, médicos, medicação, exames), regressão de comportamento, mudanças no sono, apetite etc.

Diante da hospitalização a criança se encontra física e emocionalmente debilitada, vivenciando um momento de separação do lar e mudança em sua rotina, inserida agora num ambiente que lhe é estranho e no qual é submetida a procedimentos que muitas vezes lhe causam dor e sofrimento (GABARRA, 2005).

Souza, Camargo e Bulgacov (2003) descrevem o cenário do hospital como uma realidade que exonera a criança da função de ser criança. Para eles, os aparelhos computadorizados, as luzes que piscam, os fios utilizados para o soro e transfusão de sangue, os tubos e as máscaras de oxigênio - os quais limitam seus movimentos - , as pessoas que ali trabalham com suas roupas brancas e comportamentos estereotipados, bem como a destituição de suas roupas e brinquedos, acabam retirando-a de seu papel de criança, e fazendo com que assumam o papel e a função de paciente.

$\mathrm{O}$ adoecer pode provocar muitas alterações nas vidas das crianças, desequilibrando seus organismos, despertando-lhes dor e sofrimento, o que acarretará num bloqueio de seu desenvolvimento saudável, ainda mais se a hospitalização se tratar de um processo longo (VALADARES; CARVALHO, 2006). A criança hospitalizada entrará num sofrimento emocional, ou até mesmo físico, que irá transcender a patologia inicial e que se origina no processo de hospitalização (ANGERAMI-CAMON, 2002). 
No ambiente hospitalar, as crianças têm de suportar, na maior parte das vezes, uma limitação de atividades, devido à própria situação de enfermidade e também devido à falta de espaço físico das instituições. As características deste ambiente as entristecem, podendo contribuir para aumentar seu sofrimento físico e psíquico (MACHADO; GIOIA-MARTINS, 2002).

Conforme já referido, a hospitalização surge na percepção da criança como uma punição, como um castigo; a equipe envolvida em seu cuidar deve observar a ocorrência desses pensamentos para poder intervir e fazer com que ela entenda o real motivo de sua internação, amenizando ,assim, seus sentimentos de punição e culpa que são tão comumente presentes (ANGERAMICAMON, 1984). A percepção da doença como uma punição também é relatada por Chiattone (1988), a autora acrescenta que as crianças acabam relacionando o surgimento da doença a fatores externos, como a desobediência à família, e com isto se sentem culpadas por seus erros, acreditando que estão recebendo uma punição que vem na forma de uma doença.

As crianças podem ter fantasias e imagens negativas a respeito do ambiente hospitalar, dos médicos, dos exames, dentre outros. Se elas já tiverem sido internadas em outras ocasiões, terão maiores condições de se adaptar e elaborar os acontecimentos, mas ainda assim terão receios quanto à sua situação, e a equipe deve estar treinada para ajudar a minimizar este medo. Na medida em que as crianças são informadas do que vai ocorrer, conseguem gradativamente elaborar o medo e, muitas vezes, colaborar na realização dos procedimentos necessários. Somente quando ela conseguir entender o verdadeiro sentido do aparecimento de sua doença é que poderá aliviar seus sentimentos de culpa e punição. (MACHADO; GIOIA-MARTINS, 2002)

De acordo com o que já foi dito anteriormente, a criança hospitalizada tem necessidades que vão além do atendimento clínico. Diante disto, no âmbito hospitalar a intervenção psicológica é essencial para se efetivar a mudança de comportamento desses pacientes, proporcionando-lhes melhor adaptação, bem como uma melhor qualidade de vida (SOARES; BOMTEMPO, 2004).

Segundo Novaes (1997), a criança-paciente deve ser percebida como uma pessoa tendo sua individualidade respeitada e o profissional deve saber ouvi-la sempre que ela tiver algo a dizer. Freitas (2008) destaca que a hospitalização e os procedimentos provenientes deste processo se constituem em experiências desagradáveis e dolorosas para as crianças; por isso, suas respostas podem ser negativas ou desfavoráveis em relação às intervenções se o fator humanização não estiver presente, pois a criança hospitalizada precisa não somente de cuidados físicos, ela também precisa ter suas necessidades emocionais e sociais atendidas.

\section{O DESENHO INFANTIL}

Há muito tempo o desenho é utilizado pelos humanos como forma de representar pensamentos, sentimentos e ações. O homem primitivo já fazia uso de sua linguagem simbólica, utilizando-os antes mesmo dos símbolos que registrassem 
especificamente a sua fala. Este simbolismo do desenho permite a comunicação desde épocas bastante precoces da vida do homem, possibilitando que o mesmo se expresse desde a infância, antes mesmo de aprender a escrever (HAMMER, 1981). Dessa maneira o desenho infantil se constitui como uma das primeiras formas de expressão, surgindo antes do desenvolvimento da leitura e da escrita.

Para Mèredieu (1999) o desenho infantil é como uma língua com seu próprio vocabulário e sintaxe. Hammer (1981) por sua vez ressalta que, por meio do desenho as crianças transmitem coisas que não conseguiriam expressar com palavras, ainda que elas estivessem conscientes dos sentimentos que as mobilizam.

Do mesmo modo, Rocha (1970) afirma que, ao desenhar espontaneamente a criança cria uma estrutura que a leva com maior facilidade em direção às suas emoções, fantasias e sentimentos.

Interpretar o desenho de uma criança é explicar o que está obscuro, traduzindo-o numa linguagem compreensível, extraindo do desenho um sentido oculto - tanto ao entendimento da criança quanto dos adultos que a cercam -, transcrevendo este sentido latente para uma linguagem verbal. O desenho é o método mais eloquente, imediato e de mais simples execução para se investigar traços de humor, de comportamento e de caráter de uma criança, assim como seus conflitos intrapsíquicos, suprindo, dessa maneira, sua dificuldade em falar de si mesma e expor seus problemas (ARFOUILLOUX, 1983).

Para Winnicott (1984) o desenho é também uma maneira de se entrar em contato com a criança e seu mundo, funcionando como mediador das relações que são estabelecidas com ela. Goldberg, Yunes e Freitas (2005) acrescentam que por meio do desenho a criança pode organizar informações e processar experiências, criando relações e construindo símbolos, desenvolvendo conceitos e representando seu universo de maneira singular, expressando ainda sentimento e autoconhecimento.

Conforme as ideias referidas acima, o desenho infantil e sua efetividade foram reconhecidos por diversos autores, os quais o colocam numa posição facilitadora das relações com a criança, e ainda como forma de expressão de sentimentos e emoções, cognição, personalidade, desenvolvimento etc. Com isso o desenho infantil se caracteriza por ser um excelente instrumento a ser aplicado em substituição ao discurso verbal da criança, podendo ainda ser associado a este discurso, complementando-o, facilitando suas associações livres.

O desenho envolve,ainda, o conceito de projeção, conceito este introduzido por Freud em 1894 (CUNHA, 1993). No sentido psicanalítico, define-se projeção como:

Operação pela qual o sujeito expulsa de si e localiza no outro - pessoa ou coisa - qualidades, sentimentos, desejos e mesmo "objetos" que ele desconhece ou recusa nele. Trata-se aqui de uma defesa de origem muito arcaica, que vamos encontrar em ação, particularmente na paranóia, mas também em modos de pensar "normais", como a superstição (LAPLANCHE; PONTALIS, 2001, p. 374). 
Ao conceito de projeção, Hammer (1981) acrescenta se tratar de um fenômeno que deve ser visto não somente como projeção de algo recalcado, mas, sobretudo, como uma forma de se colocar a experiência interna no mundo exterior; como um processo psicológico no qual as pessoas atribuem qualidades e sentimentos aos objetos do ambiente - entendendo-se por objeto as pessoas, organismos ou coisas - , sendo este conteúdo projetivo reconhecido ou não pelo sujeito como sendo algo dele.

Para Campos (2006) o uso do desenho como técnica projetiva favorece o surgimento dos conflitos mais profundos, pois estes conflitos se refletiriam melhor no papel. A respeito da interpretação dos mesmos Van Kolck (1984) observa que em todo processo de interpretação de desenhos infantis o princípio básico é de que o desenho representa o sujeito e a folha de papel seu ambiente. Com isso, entende-se que o desenho pode ser utilizado para compreender a percepção do sujeito do meio em que está inserido, bem como para promover a expressão de conflitos vivenciados a partir da interação do sujeito com o meio, com os outros e com ele mesmo.

\section{O DESENHO NO CONTEXTO DA ENFERMARIA PEDIÁTRICA}

A disponibilidade de compartilhar os sentimentos e dúvidas de crianças enfermas parece ser um grande desafio para profissionais de saúde e familiares. Pode-se supor que a grande inquietação do adulto é se deparar e lidar com os próprios sentimentos despertados por esta situação, o que pode acarretar um vácuo entre a criança doente e os adultos, levando o menor a não compartilhar os seus medos e dúvidas sobre a sua doença e hospitalização (GABARRA, 2005).

Na busca de se tentar compreender os sentimentos de crianças em situação de hospitalização, encontra-se o trabalho desenvolvido por Chiattone (1988) na pediatria do hospital brigadeiro, em São Paulo, no qual proporcionava atividades artísticas às crianças, por meio do uso de técnicas de pintura a dedo, tinta guache, com as quais as crianças desenhavam sobre seu momento de hospitalização. Por meio deste foi observado que as crianças conseguiam externalizar seus sentimentos de culpa e suas fantasias.

Sobre os desenhos, a autora acima referida relata que é bastante comum que as crianças desenhem o hospital em preto e muito grande, com os pacientes bem pequenos, demonstrando, assim, que se sentem impotentes perante a instituição. A autora acrescenta que conversar sobre o que a criança desenha é muito importante para que elas expressem suas ansiedades e medos. Outra estratégia de desenho usado pela autora consistia em fazer com que elas pintassem desenhos e contassem histórias sobre os mesmos, funcionando, assim, como um teste projetivo.

No que diz respeito às pesquisas, Freitas (2008) realizou uma cujo principal objetivo era verificar aspectos cognitivos e emocionais em crianças por meio do desenho da pessoa humana e do desenho da pessoa hospitalizada, no intuito de verificar qual das duas formas de desenho era a mais eficaz para se aplicar em crianças hospitalizadas - entende-se por mais eficaz aquele em que a criança 
conseguia se expressar melhor. A pesquisa concluiu que o desenho da pessoa hospitalizada possibilita uma melhor obtenção de dados no que diz respeito à compreensão da criança de seu quadro clínico, bem como das emoções que emergem deste, sendo excelente instrumento para ser utilizado pelo psicólogo hospitalar.

Outra pesquisa com crianças em situação de hospitalização que se utilizou de desenhos livres - bem como de inquérito seguido ao desenho - foi realizada por Gabarra (2005). Nesta, o objetivo era investigar a compreensão das crianças sobre sua doença em geral e sobre seus aspectos específicos, como tratamento, prevenção, hospitalização e medicação. Ainda pretendia verificar os sentimentos das crianças que emergiam em decorrência do adoecer e os fatores que poderiam influenciar na compreensão da hospitalização. Constatou-se que as crianças compreendiam as doenças de forma geral, e sua própria doença, a partir de suas experiências com o adoecer, com a hospitalização e a partir dos demais eventos de sua vida. Observou-se, ainda, que os fatores que interferiam na compreensão da criança sobre a doença são: idade, tempo de diagnóstico, a forma como a doença é comunicada e o apoio que esta criança possui de pessoas significativas.

Machado e Gioia-Martins (2002) desenvolveram uma pesquisa numa enfermaria pediátrica de um hospital público que consistia em analisar desenhos de crianças de ambos os sexos com o objetivo de verificar mudanças no comportamento e nas questões emocionais a partir da intervenção nas enfermarias de médicos fantasiados de palhaços que faziam parte dos doutores da alegria. A pesquisa consistiu em solicitar desenhos livres às crianças aos quais elas tinham que atribuir alguma história, após isto os doutores da alegria adentravam no leito, depois era solicitado outro desenho. As autoras perceberam que, após a atuação dos palhaços, os temas dos desenhos foram mais positivos, aparecendo neles cores mais alegres, tal como o vermelho e o rosa, enquanto que, no primeiro, prevaleceram cores como o roxo e o preto.

Como demonstrado, o desenho infantil e seu uso no hospital já são considerados relevantes por diversos autores - alguns dos quais foram citados -, sendo este instrumento utilizado em pesquisas que visam, de maneira geral, compreender as representações construídas pela criança no processo de hospitalização para, com isso, intervir junto a elas, propiciando-lhes a expressão e a elaboração dos sentimentos emergentes na hospitalização.

\section{CONSIDERAÇÕES FINAIS}

O desenho infantil consiste num meio pelo qual a criança consegue expressar suas vivências, seus conflitos, suas emoções, ou seja, todos os sentimentos que emergem a partir de situações de seu cotidiano. Num contexto hospitalar, o desenho pode se revelar um instrumento eficaz na comunicação do que a criança sente, revelando seu sofrimento psíquico e suas angústias, possibilitando, a partir disso, intervenções neste sentido. 
Durante a hospitalização, muitas vezes os conflitos e as dificuldades da criança não são identificados pela equipe. Neste momento, a introdução de técnicas que permitam a expressão da criança irá beneficiá-la, possibilitando atendimento e avaliação adequados que abarquem sentimentos provenientes da doença e da internação. No contexto hospitalar, o desenho pode ser um associado na investigação dos conceitos de saúde e de doença; pode ainda mediar processos psicológicos, permitindo a representação de pensamentos e sentimentos por meio do grafismo.

O uso do desenho como instrumento que propicia a expressão da criança no contexto do hospital pressupõe também a importância dos profissionais de saúde neste processo, especialmente dos psicólogos, pois estes devem intervir considerando os reflexos da doença e do internamento no psiquismo infantil, realizando atendimentos nos quais as crianças possam ser efetivamente compreendidas. Além disso, este profissional pode ainda mediar a relação da criança com outros integrantes da equipe de saúde; orientando, ainda, a família no cuidado com a criança-paciente, clarificando-lhes as mudanças ocorridas no comportamento infantil que são tão comuns durante o processo de internação.

$\mathrm{O}$ desenho consiste em um dos instrumentos que podem ser agregados ao tratamento para que a criança possa se expressar durante o processo de hospitalização. Além dele, outros meios também podem ser utilizados, a exemplo das vivências lúdicas que permitem que a criança exerça sua infância no espaço do hospital, favorecendo seu atendimento integral. A percepção do Ser em sua integralidade é essencial nas intervenções hospitalares e o grafismo infantil, dentre outras funções, é um fator que pode contribuir para o planejamento do atendimento integral e humanizado à criança hospitalizada.

\section{REFERÊNCIAS}

ALMEIDA, F. A. Lidando com a morte e o luto por meio do brincar: a criança com câncer no hospital. Boletim de Psicologia, São Paulo, v. 55, n. 123, p. 149-167, dez. 2005. Disponível em: <http://pepsic.bvs-psi.org.br/scielo.php?script=sci arttext\&pid=S0006-59432005000200003\&lng=pt\&nrm=iso $>$. Acesso em: 7 jan. 2008.

ANGERAMI-CAMON, V. A. Psicologia Hospitalar: a atuação do psicólogo no contexto hospitalar. São Paulo: Traço, 1984.

ANGERAMI-CAMON, V. A. Psicologia Hospitalar: teoria e prática. São Paulo: Pioneira Thonsom, 2002.

ARFOUILLOUX, J. C. A entrevista com a criança: a abordagem da criança através do diálogo, do brinquedo e do desenho. 3. ed. Rio de Janeiro: Zahar, 1983. 
BARUS-MICHEL, J. Sofrimento e perda de sentido: condições psicossociais e clínicas. PSIC: Revista de Psicologia da Vetor Editora, São Paulo, v. 4, n.1, p. 54-71, jul./dez. 2003. Disponível em: <http://pepsic.bvs-psi.org.br/scielo. php? script $=$ sci_arttext\&pid $=$ S 1676-73142003000100007\&lng=es\&nrm=>. Acesso em: 7 jan. 2008.

CAMPOS, D. M. S. O teste do desenho como instrumento de diagnóstico da personalidade: validade, técnica de aplicação e normas de interpretação. 38. ed. Petrópolis: Vozes, 2006.

CHIATTONE, H. B. C. A criança e a hospitalização. In: ANGERAMI-CAMON, V. A. (Org.). A Psicologia no hospital. São Paulo: Pioneira, 1988. p. 95-102.

CUNHA, J. A. Psicodiagnóstico -R. 4. ed. Porto Alegre: Artes Médicas, 1993.

DI LEO, J. H. A interpretação do desenho infantil. Porto Alegre: Artes Médicas, 1985.

FONGARO, M. L.; SEBASTIANI, R W. Roteiro de avaliação psicológica aplicada ao hospital geral. In: E a psicologia entrou no hospital. São Paulo: Pioneira, 1996. p. 104-200.

FREITAS, P. G. O desenho da figura humana e o desenho da pessoa doente na avaliação psicologia de crianças hospitalizadas. 2008. Dissertação (Mestrado)Universidade de São Paulo, São Paulo, 2008.

GABARRA, L. M. Crianças hospitalizadas com doenças crônicas: a compreensão da doença. 2005. Dissertação (Mestrado) - Universidade Federal de Santa Catarina, Florianópolis, 2005.

GOLDBERG, L. G.; YUNES, M. A. M.; FREITAS, J. V. O desenho infantil na ótica da ecologia do desenvolvimento humano. Psicologia em Estudo, Maringá, v. 10, n. 1, p. 97-106, jan./abr. 2005. Disponível em: <http://www.scielo.br/pdf/ pe/v10n1/v10n1a11.pdf $>$. Acesso em: 28 set. 2008.

HAMMER, E. F. Aplicações clínicas dos desenhos projetivos. Rio de Janeiro: Interamericana, 1981.

LAPLANCHE, J. PONTALIS, J. B. Vocabulário de psicanálise. 4.ed. São Paulo: Martins Fontes, 2001.

MACHADO, M. M. P.; GIOIA-MARTINS, D. A criança hospitalizada: espaço potencial e o palhaço. Boletim de Iniciação Científica da Universidade presbiteriana Mackenzie, São Paulo, v. 3. n. 1. p. 34-52, 2002. Disponível em: $<$ http://www.mackenzie.br/fileadmin/Graduacao/CCBS/Cursos/Psicologia/ boletins/3/3_a_crianca_hospitalizada.pdf $>$. Acesso em: 10 fev. 2008. 
MÈREDIEU, F. O desenho infantil. 6. ed. São Paulo: Cultrix, 1999.

NOVAES. L. H. V. S. Um novo paradigma para um novo pediatra. Revista Pediatria Moderna, São Paulo, v. 33, n. 5, p. 299-308, maio 1997.

OLIVEIRA, H. A enfermidade sob o olhar da criança hospitalizada. Cadernos de Saúde Pública, Rio de Janeiro, v.9, n.3, p. 323-332, jul./set., 1993.

PIAGET, J. A formação do símbolo na criança: imitação, jogo e sonho, imagem e representação. Rio de Janeiro: J. Zahar, 1971.

ROCHA, Z. A. B. Investigação dinâmica da mente infantil. Petrópolis: Vozes, 1970.

SOARES, M. R. Z.; BOMTEMPO, E. Preparação da criança hospitalizada para procedimentos médicos. Revista Estudos de Psicologia, Campinas, v. 21, n. 1, p. 53-64, jan./abr. 2004. Disponível em: <http://www.scielo.br/pdf/estpsi/v21n1/ a05v21n1.pdf>. Acesso em: 7 jan. 2008.

SOUZA, S. V.; CAMARGO, D.; BULGACOV, Y. L. M. A expressão da emoção por meio do desenho de uma criança hospitalizada. Psicologia em Estudo, Maringá, v. 8, n. 1, p. 101-109, jan./jun. 2003.

VALLADARES, A. C. F. Arteterapia com crianças hospitalizadas. 2003. Dissertação (Mestrado)-Universidade de São Paulo, Ribeirão Preto, 2003.

VAlladARES, A. C. A.; CARVAlHO, A. M. P. Promoção de habilidades gráficas no contexto da hospitalização. Revista Eletrônica de Enfermagem, Goiás, v. 8, n. 1, p. 128-133, jan./abr. 2006. Disponível em: <http://www.fen.ufg. br/revista/revista8_1/original_16.htm>. Acesso em: 2 fev. 2008.

VAN KOLCK, O. L. Testes projetivos no diagnóstico psicológico. São Paulo: EPU, 1984.

WINNICOTT, D. W. Consultas terapêuticas em psiquiatria infantil. Rio de Janeiro: Imago, 1984.

Recebido em: julho de 2009

Aceito em: abril de 2010 